\title{
Contribution of the Urine Dipstick to Urinary Tract Infection Diagnosis among Children in Two Hospitals in Cotonou-Benin
}

\author{
Godonou Gratien Sagbo', Fredias Sogbo², Honorat Francis Lalya', Joseph Agossou ${ }^{3}$, \\ Yevedo Tohodjèdé ${ }^{*}$, Florence Alihonou1, Gilles Bognon ${ }^{4}$, Diane Ahinonhossou${ }^{1}$, \\ Afolabi Dissou ${ }^{2}$, Blaise Ayivi ${ }^{1}$ \\ ${ }^{1}$ Pediatric Unit of the Hubert Koutoukou Maga University Teaching Hospital (CNHU-HKM), Cotonou, Benin \\ ${ }^{2}$ Bacteriology Unit of CNHU-HKM, Cotonou, Benin \\ ${ }^{3}$ Mother \& Child Department, Faculty of Medicine, University of Parakou, Parakou, Benin \\ ${ }^{4}$ Hospital of Porto-Novo, Porto-Novo, Benin \\ Email: godsagbo@yahoo.fr, sogbofredias@yahoo.fr, francislalya@gmail.com, *yeredo05@yahoo.fr, alihonouy@yahoo.com, \\ bognongilles@gmail.com, dianeahinou@yahoo.fr, affolabi_dissou@yahoo.fr, blaise_ayivi@yahoo.fr
}

How to cite this paper: Sagbo, G.G., Sogbo, F., Lalya, H.F., Agossou, J., Tohodjèdé, Y., Alihonou, F., Bognon, G., Ahinonhossou, D., Dissou, A. and Ayivi, B. (2017) Contribution of the Urine Dipstick to Urinary Tract Infection Diagnosis among Children in Two Hospitals in Cotonou-Benin. Open Journal of Pediatrics, 7, 272-281.

https://doi.org/10.4236/ojped.2017.74031

Received: September 19, 2017

Accepted: November 18, 2017

Published: November 21, 2017

Copyright () 2017 by authors and Scientific Research Publishing Inc. This work is licensed under the Creative Commons Attribution International License (CC BY 4.0).

http://creativecommons.org/licenses/by/4.0/

\begin{abstract}
Introduction: Urinary tract infections are a daily concern in pediatric nephrology with long-term risks for high blood pressure and renal failure. The purpose of this study was to determine the contribution of a urine dipstick (UD) to the diagnosis of urinary infections among children at the CNHU-HKM and the Lagoon Mother and Child University Teaching Hospital (CHU-MEL) of Cotonou. Patients and Methods: This study is a cohort, descriptive and analytical study focused on children with suspected urinary infections in the pediatric units of the CNHU-HKM and CHU-MEL of Cotonou from March 25 to August 25, 2015. Results: Two hundred and four children out of a total of 5125 admitted children (4\%) presented with at least one clinical sign of a urinary tract infection. Children under 36 months of age were predominant (41\%). The main clinical signs of urinary infections were fever $(60.8 \%)$ and urinary disorders (38.2\%). The urinary dipstick test was positive in 145 children (71.2\%). A urinary tract infection was confirmed by urine culture in 38 children (18.6\%). In cases with leucocyturia- and nitrituria-positive urine dipstick tests, the sensitivity was estimated to be $13.2 \%$, and the specificity was $95.2 \%$, with a negative predictive value (NPV) of $82.8 \%$. Only when the leucocyturia test was positive, the sensitivity was $76.3 \%$, and the specificity was $31.9 \%$. When the leucocyturia test was negative, the specificity was estimated to be $94 \%$, and the sensitivity was $83 \%$ in the nitrituria-positive cases and $15.8 \%$ in the nitrituria-negative cases. The main isolated pathogens were Escherichia coli $(\mathrm{n}=21)$ and Klebsiella pneumoniae $(\mathrm{n}=14)$. Conclusion: In our environment, a negative leucocyturia test may help exclude urinary tract infections in most cases.
\end{abstract}




\section{Keywords}

Urinary Tract Infection, Urinary Dipstick Test, Urine Culture

\section{Introduction}

Urinary infections play an important role in renal pathology due to their frequencies among both genders and all ages [1]. Urinary infections are of particular importance during childhood, because they are responsible for considerable morbidity during the acute phase of the disease and may cause high blood pressure or renal failure in the long term. Cytobacteriological examination of urine (CBEU) is the reference test for the diagnosis of urinary tract infections and helps isolate the pathogen and test its sensitivity to antibiotics [2]. However, this test is relatively expensive in our environment, and the result is not immediately available, which impedes the ability to make a quick decision regarding care. A urine dipstick test provides guidance for urinary tract infections [3] [4] by testing for the presence of leukocytes or nitrites in the urine, which helps recommend probabilistic antibiotic therapy based on the local bacterial ecology, especially when there is a fear of pyelonephritis of unknown severity. The aim of this study was to determine the urinary dipstick's contribution to the diagnosis of urinary tract infections among children in the pediatric units of two university teaching hospitals located in the city of Cotonou.

\section{Materials and Methods}

This study was a cross-sectional, descriptive and analytical study conducted from March 25 to August 25, 2015 (i.e., over a five-month period). The study was conducted in the pediatric units of the National University Teaching Hospital (CNHU) and Lagoon Mother and Child University Teaching Hospital (CHU-MEL) of Cotonou. Each hospital received an average of 5000 children per year. The study focused on children aged one month to 15 years attended for medical examinations in these health centers. This study involved children presenting with signs suggestive of a urinary tract infection, including unexplained or persistent fever (lasting more than 5 days), urinary disorders (dysuria, acute urine retention, weak urine stream, pyuria, or pollakiuria) or gastrointestinal disorders (abdominal pains or vomiting). A child may show persistent fever associated with urinary or gastrointestinal disorder. The sampling was systematic and consecutive. All eligible patients were subjected to both a urinary dipstick test and cytobacteriological examination of freshly issued urine that had remained in the bladder for at least two hours. Samples were collected with aseptic techniques in either the middle of the urine stream among older children or by laying a urine bag left in place for no more than 30 minutes in the youngest children. Two urine samples were successively collected: one for the urine dipstick test and the second for the cytobacteriological examination of urine. The urine dipstick trademark was the 
COMBI UriScreen $10 \mathrm{SL}$, and the dipsticks were not expired and were stored in a cool place. For the urine sample used for the dipstick test, a dipstick was immersed in the urine and read after two minutes to identify leukocyte esterase and/or nitrates. The reading was performed based on comparison with the abacus on the box. The results were noted as the number of crosses and varied from 0 to four cross traces $(++++)$.

The second urine sample was immediately transported to the laboratory for the cytobacteriological urine examination. The cytobacteriological urine examination was considered positive when the leucocyturia was higher than $10^{4}$ per $\mathrm{mL}$ and when the bacteriuria complied with the recommendations of the French Society of Microbiology [5]. Pathogens were isolated by culture and their sensitivity to antibiotics determined. The study variables were demographic variables (age and gender), warning signs of a urinary tract infection, variables for a biological diagnosis of a urinary tract infection (urine dipstick, leucocyturia, or nitrituria), variables for a positive diagnosis of a urinary tract infection (cytobacteriological examination of urine) and the bacterial sensitivity test to antibiotics results.

The collected data were recorded and processed using the Epi Info software version 7.1.1.7. The performance of the urine test with the dipstick compared to the standard cytobacteriological examination of urine was assessed based on the sensitivity, specificity and negative and positive predictive values of the urine dipstick parameters. The positive predictive value (PPV) was defined as the ratio of valid results to the test's positive results. The negative predictive value (NPV) was the ratio of valid results to all negative results. The sensitivity was the ratio of the total patients that the test was likely to detect in the collectivity, and the specificity was considered the ratio of healthy subjects confirmed as such by the test's negative result. Informed and written consent was obtained from the parents before any children were included.

\section{Results}

\subsection{Epidemiological Aspects}

\subsubsection{Frequency}

During the study, 204 children presented with one or more signs suggestive of a urinary tract infection out of the total 5125 children admitted during the study period in the two hospitals, for a frequency of $4 \%$.

\subsubsection{Age and Gender}

Among those 204 children, 85 were under 3 years of age (41.6\%), and 106 were males (52\%) versus 98 females (48\%) for a gender ratio (M/F) of 1.08 . The distribution based on the age groups and genders of the children is shown in Table 1.

\subsection{Clinical Aspects}

The clinical signs suggestive of a urinary tract infection were fever $(124 / 204,60.8 \%)$, 
Table 1. Distribution of children with a suspected urinary tract infection according to age and gender.

\begin{tabular}{|c|c|c|c|}
\hline \multirow{2}{*}{ Age (months) } & \multicolumn{2}{|c|}{ Gender } & \multirow{2}{*}{ Tota } \\
\hline & Male N (\%) & Female N (\%) & \\
\hline $1-3$ & $8(07.5)$ & $2(02.0)$ & 10 \\
\hline $3-12$ & $14(13.2)$ & $18(18.4)$ & 32 \\
\hline $12-36$ & $26(23.5)$ & $17(17.3)$ & 43 \\
\hline $36-60$ & $15(14.2)$ & $15(15.3)$ & 30 \\
\hline$>60$ & $43(40.6)$ & $46(46.9)$ & 89 \\
\hline Total & 106 & 98 & 204 \\
\hline
\end{tabular}

Table 2. Distribution of children with a confirmed urinary tract infection according to age and gender.

\begin{tabular}{cccc}
\hline \multirow{2}{*}{ Age (months) } & \multicolumn{2}{c}{ Gender } & \multirow{2}{*}{ Total } \\
\cline { 2 - 3 } & Male & Female & \\
\hline $1-3$ & $2(10.5 \%)$ & 0 & 2 \\
$3-12$ & $5(26.3 \%)$ & $2(10.5 \%)$ & 7 \\
$12-36$ & $9(47.4 \%)$ & $3(15.8 \%)$ & 12 \\
$36-60$ & $2(10.5 \%)$ & $2(10.5 \%)$ & 4 \\
$>60$ & $1(5.3 \%)$ & $12(63.2 \%)$ & 13 \\
Total & 19 & 19 & 38 \\
\hline
\end{tabular}

urinary disorders $(78 / 204,38.2 \%)$ and digestive disorders (14/204, 16.6\%). Notably, a child may show persistent fever associated with a urinary or gastrointestinal disorder.

\subsection{Biological Diagnosis of Urinary Tract Infections}

The urine dipstick test was positive in 145 out of the 204 involved children (71.2\%). A urinary tract infection was confirmed by cytobacteriological examination of urine in 38 out of the 204 included children (18.6\%). The distribution based on the age groups and genders of the children with confirmed urinary tract infections is indicated in Table 2 (page 4).

\subsection{Comparison of the Urine Dipstick Test Results with the Cytobacteriological Examination of Urine}

The cytobacteriological examination of urine (CBEU) confirmed infections in 23 children with positive leucocyturia. Nine children with negative leucocyturia and/or nitrituria tests had a urinary tract infection confirmed by CBEU as indicated in Table 3 (page 5).

Additionally, all nine children with urinary tract infections with a negative urine dipstick test were under 36 months of age. The signs that made us suspect a urinary tract infection in those nine children were an unexplained fever and 
Table 3. Agreement between the urine dipstick test and CBEU results.

\begin{tabular}{ccc}
\hline \multirow{2}{*}{ Urine Dipstick } & \multicolumn{2}{c}{ CBEU } \\
\cline { 2 - 3 } & Positive n (\%) & Negative n (\%) \\
\hline $\mathrm{L}^{+} \mathrm{N}^{-}$ & $23(60.5 \%)$ & $105(63.3 \%)$ \\
$\mathrm{L}^{-} \mathrm{N}^{+}$ & $1(2.6 \%)$ & $2(1.2 \%)$ \\
$\mathrm{L}^{+} \mathrm{N}^{+}$ & $5(13.2 \%)$ & $8(4.8 \%)$ \\
$\mathrm{L}^{-} \mathrm{N}^{-}$ & $9(23.7 \%)$ & $51(30.7 \%)$ \\
Total & $38(100 \%)$ & $166(100 \%)$ \\
\hline
\end{tabular}

$\mathrm{L}=$ Leukocytes; $\mathrm{N}=$ Nitrites $;+=$ Positive $;-=$ Negative.

Table 4. Performance of the urine test with urinary dipstick compared to the CBEU.

\begin{tabular}{ccccc}
\hline & PPV (\%) & NPV (\%) & Se (\%) & Sp (\%) \\
\hline $\mathrm{L}^{+} \mathrm{N}^{-}$ & 20.4 & 85.0 & 76.3 & 31.9 \\
$\mathrm{~L}^{-} \mathrm{N}^{+}$ & 15.8 & 37.6 & 83.0 & 94.0 \\
$\mathrm{~L}^{+} \mathrm{N}^{+}$ & 38.6 & 82.8 & 13.2 & 95.2 \\
$\mathrm{~L}^{-} \mathrm{N}^{-}$ & 37.6 & 83.0 & 15.8 & 94.0 \\
\hline
\end{tabular}

$\mathrm{L}=$ Leukocyte; $\mathrm{N}$ = Nitrite; $\mathrm{Se}=$ Sensitivity; $\mathrm{Sp}=$ Specificity.

persistent diarrhea.

\subsection{Performance of the Urine Dipstick Test Compared to the Cytobacteriological Examination of Urine}

In cases with positive leucocyturia and nitrituria urine dipstick tests, the sensitivity was $13.2 \%$ and the specificity $95.2 \%$, with an NPV of $82.8 \%$. When only leucocyturia tested positive using the urine dipstick, the sensitivity was estimated to be $76.3 \%$ and the specificity was only $31.9 \%$. However, when the leucocyturia test was negative, the specificity was estimated to be $94 \%$ and the sensitivity was estimated to be $83 \%$ in cases with a positive nitrituria test and $15.8 \%$ in cases with a negative nitrituria test. The comparison of the performance results obtained with the urine dipstick test and the cytobacteriological examination of urine is summarized in Table 4 (page 5).

\subsection{Causal Pathogens and Bacterial Sensitivity Test to Antibiotics}

The main pathogens isolated by culture were Escherichia coli $(\mathrm{n}=21)$, Klebsiella pneumoniae $(\mathrm{n}=14)$, Morganella morganii $(\mathrm{n}=1)$, Pseudomonas aeruginosa $(\mathrm{n}$ $=1)$, and coagulase-negative Staphylococcus $(\mathrm{n}=1)$.

The antibiotics most active on Escherichia coli were Fosfomycin (18/21), Netilmycin (16/21) and Imipenem (15/21). The two antibiotics most active on Klebsiella pneumoniae were Fosfomycin (14/21) and Imipenem (13/21). The findings of the combined bacterial sensitivity tests to antibiotics for those two pathogens indicated that they were more sensitive to Fosfomycin, Imipenem and Netilmycin. Figures 1-3 show the distributions according to the sensitivity to those antibiotics 


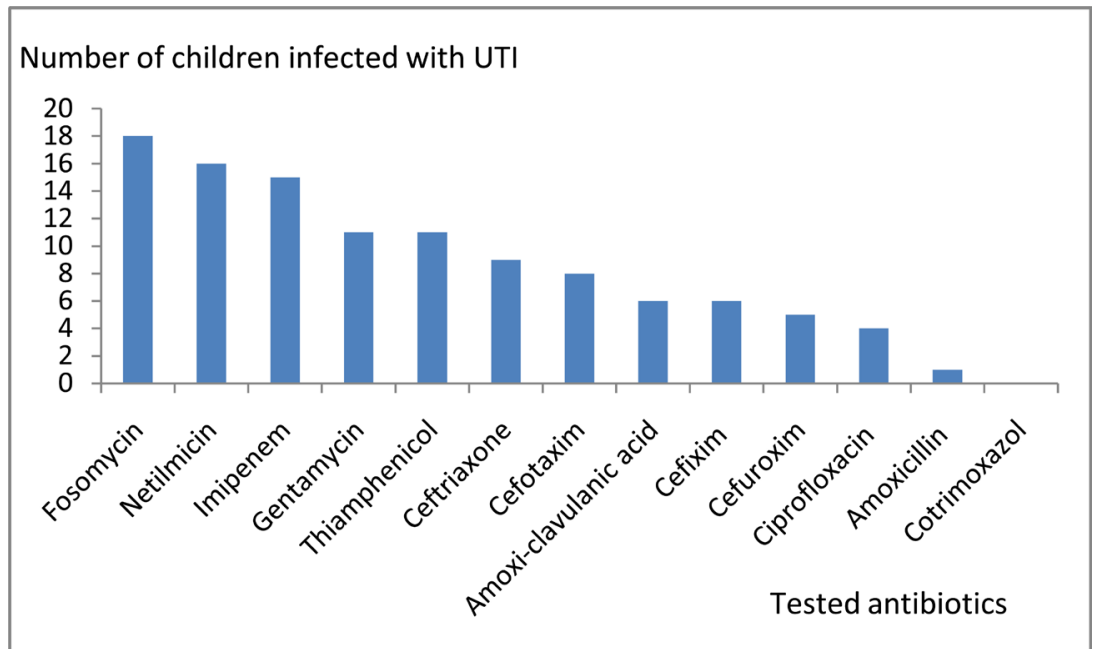

Figure 1. Distribution according to the sensitivity of Escherichia coli to antibiotics.

Figure 2. Distribution according to the sensitivity of Klebsiella pneumoniae to antibiotics.

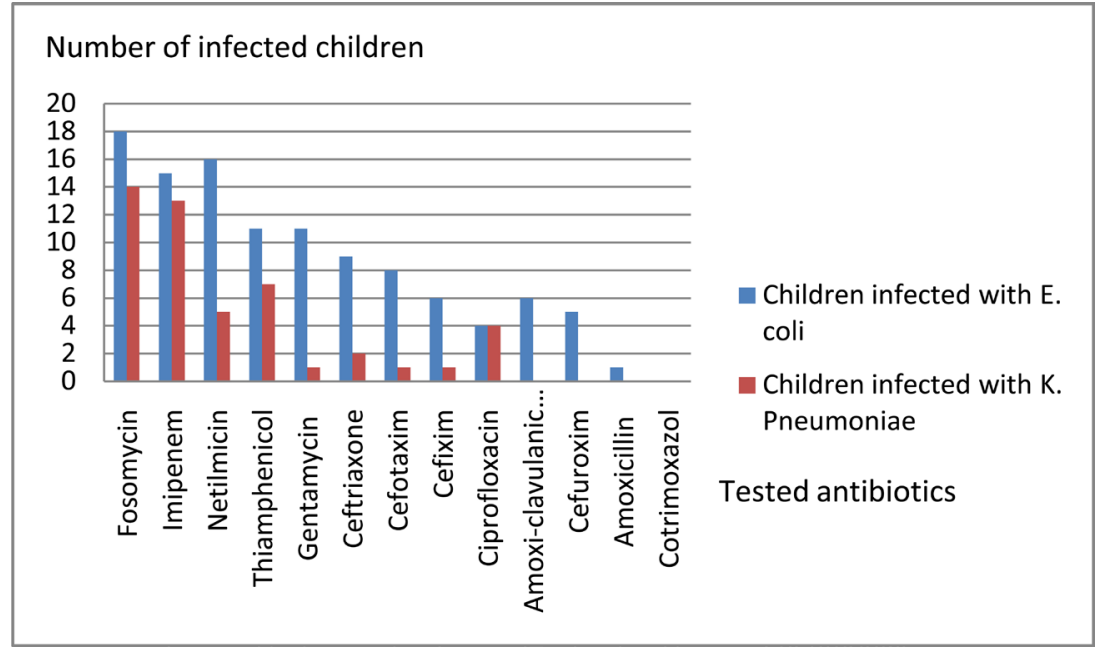

Figure 3. Distribution according to the sensitivity of Escherichia coli and Klebsiella pneumoniae to antibiotics. 
of each of the pathogens individually and of both pathogens simultaneously, respectively.

\section{Discussion}

This cross-sectional study highlighted the contribution of the urine dipstick test to the diagnosis of urinary tract infections in children by demonstrating that negative leucocyturia could help eliminate a urinary tract infection in our environment. Moreover, the test allowed the identification of the causal pathogens based on the bacterial sensitivity to antibiotics. However, a limitation remains regarding the small sample size.

\subsection{Sociodemographic Aspects}

In this study, the frequency of urinary tract infections was $18.6 \%$ in a sample of children who presented signs suggestive of the disease. Another African author from the same sub-region who used the same patient selection method and study protocol found a similar frequency (18.7\%) in 2009 [6]. In contrast, case control studies focused on longer durations resulted in much lower frequencies $(7.5 \%$ in France [7] and 1.3\% in Marrakech [8]). Therefore, the frequency of urinary tract infections seems to vary according to the number of children involved in the study, the method and the study duration [8] [9].

In this study, we noted a gender ratio of 1 for the children with urinary tract infections. Two other authors showed a clear female predominance in their studies [8] [10]. The predominance of urinary tract infections among the female gender may be due to the proximity of the terminal digestive tract, whereas the male reproductive system is associated with a short urethra [2]. Urinary tract infection is a disease that can occur at any age as demonstrated in this study, although another author reported that the disease was predominant in children under 36 months of age [6]. During that timeframe, the prevalence may correspond to the period of detection of the manifestations of urinary tract abnormalities [9] [11] [12]. Furthermore, similar to any infectious pediatric disease, the immaturity of the immune system may explain the major susceptibility of this age group [6].

\subsection{Performance of the Urine Dipstick Test and Its Consistency with the CBEU}

Urine dipstick tests are rapid tests based on the detection of leukocyte esterase activity, especially neutrophils, and nitrites, which indicate the presence of enterobacteria that are likely to reduce nitrates [2] [13]. The systematic use of this test is of interest in cases of suspicion of urinary tract infections when there are suggestive signs or in infants with fever without other clinical anomalies [7]. Cytobacteriological examination of urine (CBEU) confirmed a urinary tract infection in $60.5 \%$ of cases when the test was positive for only leucocyturia, with sensitivity estimated at $76.3 \%$ and specificity at $31.9 \%$. Similar results were found 
by two other authors [7] [14]. However, when the leucocyturia result was negative, the specificity was relatively high (94\%). The few negative results were observed when the number of leukocytes was low (below 15 leukocytes/mL) [8] [15]. When only nitrituria was positive, the CBEU was positive in only one child with a specificity estimated at $94 \%$ and sensitivity at $83 \%$. This result was in agreement with the findings of Bensman, who observed that the urine dipstick test had a high specificity (above 90\%) but a fairly low sensitivity (from 16\%) [14]. The low sensitivity may occur because some causal pathogens (Staphylococcus spp. and Pseudomonas spp.) do not reduce nitrates into nitrites or because urine may remain in the bladder for a sufficient time for the reduction to occur [7]. Nine children under 36 months of age had a urinary tract infection confirmed by CBEU but negative leucocyturia and nitrituria tests with the urine dipstick test. Boucharaoui et al. [8] obtained a similar result due to the young ages of the children, who had a small bladder with closer emptying; according to these authors, another issue may have been poor storage of the urine dipstick. The authors concluded that negative leucocyturia and nitrituria tests did not exclude a urinary tract infection in infants. Other authors specified that the urine dipstick test had an insufficient NPV in any young infant with a fever under three months of age and that cytobacteriological examination of the urine was necessary to assess the presence of urinary functional signs [16] [17]. In practice, the urine dipstick test may help the clinician not as a diagnostic test but instead as a rapid and simple screening tool to be interpreted depending on the clinic [13].

\subsection{Isolated Pathogens}

Escherichia coli was the most commonly isolated pathogen in this study [3] [8] [16], because its virulence confers a capacity to adhere to the urethra [16]. Next was Klebsiella pneumoniae, which was detected in 14 cases (36.8\%) in this study and with prevalence rates of $25 \%, 14 \%$ and $29 \%$ in studies conducted by other authors [1] [6] [8]. Pseudomonas aeruginosa was isolated once, and ultrasound of the urinary tract detected a malformation in this case, especially in the posterior urethra valve. This environmental pathogen is often identified in children with malformations of the urinary tract, children bearing a vesical probe, or children on an antibiotic [6]. Regardless of the isolated pathogen, the bacterial sensitivity test to antibiotics should be evaluated to adapt the treatment and evaluate bacterial resistance [1]. The bacterial sensitivity tests to antibiotics performed in this study indicated that the pathogens were sensitive to third generation cephalosporins (ceftriaxone and cefotaxime) and aminoglycosides (gentamicin and netilmycin), which was similar to reports by other authors [2] [8] [16]. However, the most important resistance observed was to amoxicillin and cotrimoxazole in this study, which was also similar to other studies [8] [18] [19]. The increased prevalence of resistance of Escherichia coli to amoxicillin and cotrimoxazole in urinary tract infections is constant and has been reported by the same authors. The irrational use of those antibiotics would have consequences for that observation. 


\section{Conclusion}

Based on the findings of this study, a urine dipstick test may be considered a diagnostic guidance test for urinary tract infections. The CBEU was positive in more than $60 \%(n=25)$ of cases when the leucocyturia test was positive. Therefore, a positive leucocyturia result does not indicate a urinary tract infection without CBEU. However, when the leucocyturia test was negative, the specificity of the urine dipstick test was estimated to be $94 \%$. In our environment, a negative leucocyturia test may help exclude a urinary tract infection in most cases. Moreover, the pathogens most commonly involved in urinary tract infections were Escherichia coli and Klebsiella pneumoniae, which were both sensitive to third-generation cephalosporins and aminoglycosides. When faced with a suspicion of pyelonephritis with a positive leucocyturia urine dipstick test, antibiotic therapy with third generation cephalosporin combined with an aminoglycoside may be starting while awaiting the CBEU results.

\section{Ethical Consideration}

This had received the authorization of the hospital administrative authorities.

\section{References}

[1] Bourquia, A., Ramdani, B., Sahni, K. and Zaid, D. (1992) Profile of Urinary Tract Infection in the Department of Renal Medicine. Médecine du Maghreb, 33, 11-16.

[2] Salomon, R. (2001) Urinary Tract Infections in Children. Journal de Pédiatrie et de Puériculture, 14, 6-12. https://doi.org/10.1016/S0987-7983(01)80003-7

[3] Bacchetta, J., Hess, L., Demede, D., Gillet, Y. and Cochat, P. (2013) Urinary Tract Infections in Children. Revue du praticien Médecine Générale, 27, 9-11.

[4] Riegel, P. (2003) Bacteriological Aspects of Nosocomial Urinary Tract Infections. Médecine et maladies infectieuses, 33, 255-265. https://doi.org/10.1016/S0399-077X(03)00178-1

[5] French Society of Microbiology (2015) Urinary Tract Infection. In REMIC. French Society of Microbiology, Ed., 165-178.

[6] Ouédraogo Yugbare, S.O., Kouéta, F., Dao, L., Minougou, J., Ouédraogo Traoré, R., Sanou, I., et al. (2012) Urinary Tract Infection in Children: Epidemiological and Bacteriological Aspects at the Charles de Gaulle University Teaching Pediatric Hospital of Ouagadougou (Burkina Faso). Mali Médical, 27, 11-17.

[7] Cochat, P., Dubourg, L., Koch Nogueria, P., Pertti, N. and Vial, M. (1998) Testing of Urines by Means of Reactive Dipstick. Archives de Pédiatrie, 5, 65-70. https://doi.org/10.1016/S0929-693X(97)83470-7

[8] Bouskraoui, M., Ait Sab, I., Draiss, G., Bourrouss, M. and Sbihi, M. (2010) Epidemiology of Urinary Tract Infection in Children in Marrakech. Archives de Pédiatrie, 17, 177-178. https://doi.org/10.1016/S0929-693X(10)70921-0

[9] Sagbo, G.G., Alao, M.J., Lalya, H.F., Gbénou, A.S. and Fiogbé, M. (2013) Malformations of the Urinary Tract Detected through Urinary Tract Infection among Children in Clinics of Cotonou. Mother and Child Health, 10, 1-5. https://doi.org/10.4303/cmch/C120104

[10] Ansari, B.M., Jewekes, F. and Davies, S.G. (1995) Urinary Tract Infection in Child- 
ren Part I: Epidemiology, Natural History, Diagnosis and Management. Journal of Infection, 30, 3-6. https://doi.org/10.1016/S0163-4453(95)92613-5

[11] Nademi, Z., Clark, J., Richards, C.G., Walshaw, D. and Cant, A.J. (2001) The Causes of Fever in Children Attending Hospital in the North of England. Journal of Infection, 43, 221-225. https://doi.org/10.1053/jinf.2001.0920

[12] Kahloul, N., Charfeddine, L. and Amri, F. (2010) Malformative uropathies in Children: Study of 71 Cases. Journal de Pédiatrie et de puériculture, 23, 131-137. https://doi.org/10.1016/j.jpp.2009.10.004

[13] Raymond, J. and Sauvestre, C. (1998) Microbiological Diagnosis of Urinary Tract Infections in Children. Interest of Rapid Tests. Archives de Pédiatrie, 5, 260-265. https://doi.org/10.1016/S0929-693X(98)80145-0

[14] Bensman, A., Dunan, O. and Ulinski, T. (2010) Urinary Tract Infection in Children. Pediatric Nephrology, 6, Article ID: 12971310

[15] Aitouamar, H., Chkitate, B., Jabourik, F., Bentahila, A., Routchi, A. and Belhadj, A.M. (1999) Practical Interest of Urinary Reactive Dipsticks in Children. Médecine du Maghreb, 78, 13-15.

[16] AFSSAPS (2007) Diagnosis and Antibiotic Therapy of Community Bacterial Urinary Tract Infections in Infants and Children: Recommendations. Archives de Pédiatrie, 14, 943-950. https://doi.org/10.1016/j.arcped.2007.03.004

[17] Nathanson, S. (2015) Screening of Urinary Tract Infection through Urine Dipstick Test. Médecine Thérapeutique Pédiatrie, 18, 91-96.

[18] Vu-Thien, H. (1998) Sensitivity to Antibiotics of Bacteria Isolated from Urinary Tract Infections in Children. Archives de Pédiatrie, 5, 266-268. https://doi.org/10.1016/S0929-693X(98)80146-2

[19] Prere, M.F., Licznar, P., Decramer, S. and Fayeto, O. (2004) Escherichia coli of Urinary Tract Infections and Acute Pyelonephritis in Children: 1\% of Strains Are Resistant to Some Third Generation Cephalosporins. Pathologie Biologie, 52, 49. 